\title{
Crows and pigeons differ under autoshaping
}

\author{
LINDA J. PALM and ROBERT W. POWELL \\ University of South Florida, Tampa, Florida
}

\begin{abstract}
Common crows and pigeons were studied under a conventional autoshaping procedure. In addition to measures of keypecking behavior, each subject was directly observed during the experimental sessions. The pigeons showed somewhat greater keypecking than crows did, but only one bird developed consistent responding. All of the pigeons oriented toward the response key when it was illuminated, and they all made pecking motions toward the illuminated key. None of the crows oriented toward the response key, but instead generally oriented toward the food hopper. The crows displayed little pecking behavior. The behavioral differences between species observed here seem to derive from the very substantial ecological differences between crows and pigeons.
\end{abstract}

It has previously been reported that both common crows (Corvus brachyrhynchos) and fish crows (Corvus ossifragus) show very little responding both under conventional autoshaping procedures and under positive automaintenance (Powell, Kelly, \& Santisteban, 1975). Similarly, crows seem to respond much less when switched from responsedependent to response-independent reinforcement (Powell \& Kelly, 1979) than do pigeons (Lowe \& Harzem, 1977). The most obvious explanation for this apparent species difference, that crows are disinclined to keypeck for food reinforcers, has been empirically refuted (Powell, 1972, 1974).

Our efforts to compare learning and performance in crows and pigeons have been founded on two important considerations: (1) Crows and pigeons are ecologically dissimilar, and (2) the two species are quite similar in size and general morphology. The first point suggests that behavioral principles encompassing both of these species would have considerable generality. Because of the second point, comparisons can be made under highly similar, if not identical, experimental conditions.

The present experiment was undertaken to provide a direct comparison of responding under autoshaping by crows and pigeons. A major focus of this research involved direct observations of behavior in both species during the experimental sessions.

\section{METHOD}

\section{Subjects}

Six adult white Carneaux pigeons and six adult common crows, all experimentally naive, were used. The pigeons were obtained from a commercial supplier in South Carolina and had been maintained in individual cages for approximately 2 years. The crows were obtained from commercial suppliers in Wisconsin and Florida and had been housed in individual cages for 1 to 3 years. The birds were maintained at ap-

This paper is based on part of a dissertation submitted to the University of South Florida by the first author, in partial fulfillment of the requirements for the Ph.D. degree. Send reprint requests to R. W. Powell, Department of Psychology, University of South Florida, Tampa, FL 33620 . proximately $85 \%$ of their free-feeding weights throughout the experiment. All subjects were housed in individual cages with water and grit freely available.

\section{Apparatus}

The apparatus included two standard pigeon test chambers (Lehigh Valley Model 1519 C) measuring $15.5 \times 15.4 \times 132 \mathrm{~cm}$, and each containing two translucent response keys. The chamber in which the crows were studied had been modified by enlarging the opening to the food hopper. Otherwise, the chambers were identical. One response key remained dark and inoperative. The other key, located on the right side of the intelligence panel, was illuminated by white light $(7 \mathrm{~W}, 28-$ $\mathrm{V} \mathrm{dc}$ ), and was operated by a force of $15 \mathrm{~g}$ or more. The reinforcer was Top Choice for the crows and Purina Pigeon Checkers for the pigeons. Reinforcement time was $2.5 \mathrm{sec}$ for all birds. During food presentations, the response key was turned off, and a 7-W bulb illuminated the food hopper. Constant illumination of the chamber was provided by a $28-\mathrm{V}$ dc houselight. An exhaust fan and a noise generator provided ventilation and masking noise, respectively. Data were recorded by digital counters and Gerbrands cumulative recorders located in an adjacent room.

\section{Procedure}

All birds first received magazine training during which the food hopper was presented for $2.5 \mathrm{sec}$ at 30 -sec intervals until they reliably approached and ate from the hopper. Following magazine training, all of the subjects were exposed to an autoshaping procedure. The keylight was illuminated with white light for $8 \mathrm{sec}$, followed by a 2.5 -sec presentation of the food tray at the offset of the light. A variable intertrial interval (ITI) having a mean of $60 \mathrm{sec}$ was used. These parameters have been found to be effective for the establishment of autoshaping in pigeons (Brown \& Jenkins, 1968; Terrace, Gibbon, Farrell, \& Baldock, 1975). The keylight was dark between trails. Keypecks during the ITI and during the trial were counted separately but had no scheduled consequences. Relatively short sessions were used in order to minimize satiation effects in the crows. All subjects were exposed to this procedure until 20 sessions ( 500 trials) had been completed.

\section{RESULTS}

The cumulative number of within-trial responses across the 20 autoshaping sessions are shown in Figure 1. All six pigeons responded at some time during this phase. Five of these birds had responded by the end of the second session, but Pigeon 314 did not respond until the seventh session. The mean trial of the first keypeck response was 

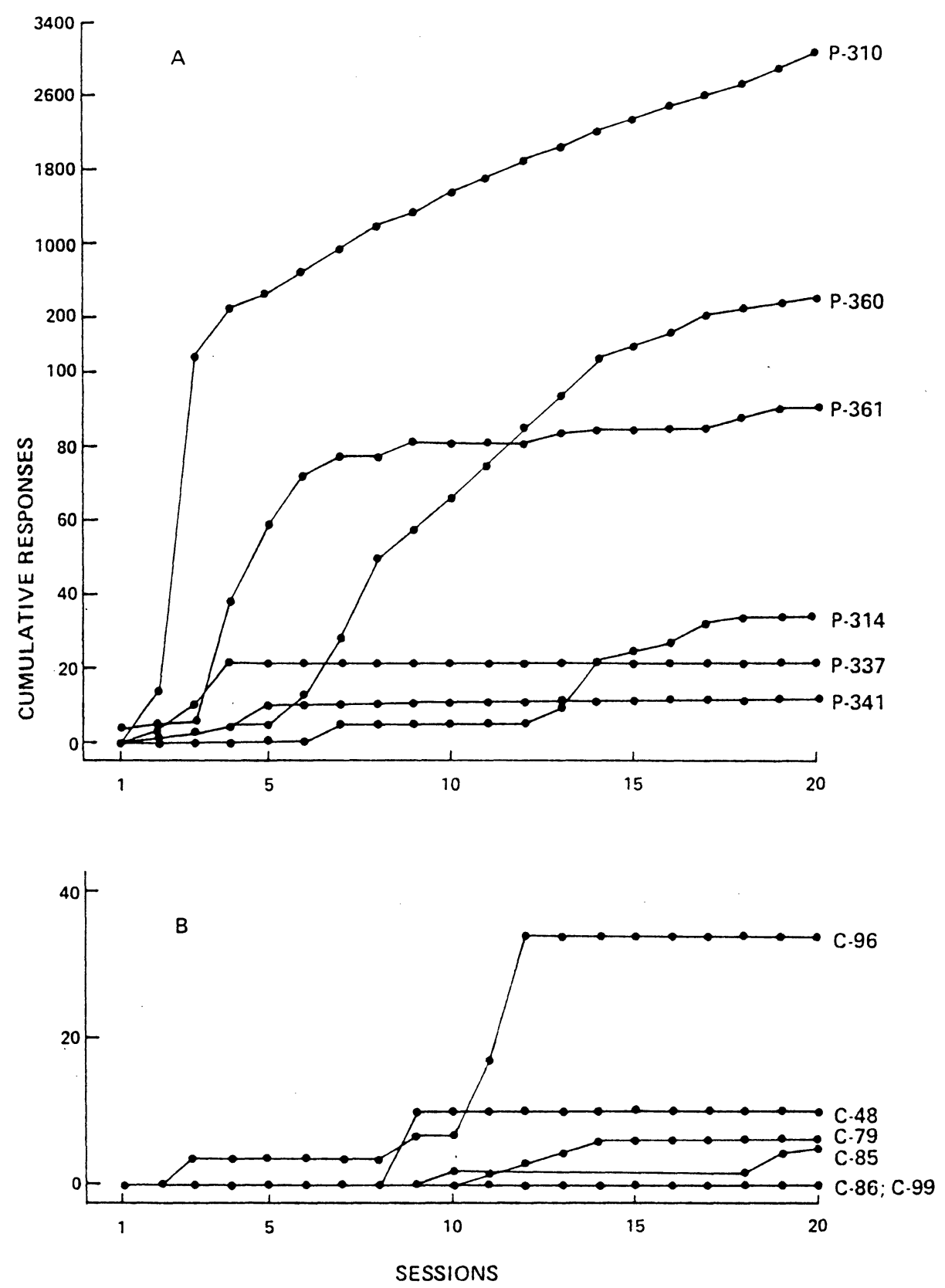

Figure 1. Cumulative number of within-trial responses for each pigeon (Panel A) and each crow (Panel B) across autoshaping sessions.

54 , with a range of 16 to 161 trials. Only one pigeon (P-310) developed and maintained a high rate of keypecking throughout the 8-sec trials, with a mean rate of 6.9 responses per trial over sessions 3-20. Pigeon 360 showed an appreciably lower rate of responding, although after the fifteenth session, this bird was pecking at an average of 2.3 responses per trial. The remaining four pigeons did not develop consistent keypecking. Little intertrial keypecking was recorded, with a mean of 1.6 responses per session for these four pigeons. Pigeon 310 made a substantially higher number of intertrial keypecks, with a mean of 11.8 per session, and Pigeon 360 averaged 4.7 intertrial responses per session.

None of the six crows exposed to the autoshaping procedure developed reliable keypecking. Two crows (C-86 and C-99) never pecked the keylight, while the remaining crows made at least one within-trial response. The mean trial of the first response was 194, with a range of 67 to 252 trials. With the exception of C-96, intertrial keypecks were infrequent, and the few recorded intertrial responses 
occurred during one or two sessions. Crow 96 made intertrial responses during eight autoshaping sessions, with a mean of 20.8 responses over these sessions.

All 12 birds were observed on a daily basis throughout the autoshaping phase, and a striking behavioral difference between species was noted. At trial onset, all six pigeons moved immediately toward the keylight and stood with their heads directly in front of the key for the duration of the trial. Pigeons 310 and 360 directed pecks at the keylight, while the other four pigeons moved their heads rapidly from side to side in front of the lighted key. These head movements were often accompanied by pecking motions at and around the key. The majority of these pecks were of insufficient force to operate the microswitch and thus be recorded as a response.

In contrast to the pigeons, the crows showed little or no orientation to the keylight. Two crows (C-86 and C-99) crouched directly in front of the opening to the food hopper throughout each autoshaping session and never displayed any head or body movements in the direction of the key. Crows 96 and 48 generally stood in front of the hopper opening during sessions and engaged in vigorous pecking of the floor and the intelligence panel following food presentations. Crow 79 developed a stereotyped pattern which consisted of turning complete circles in the chamber after most food presentations. During these circular movements, Crow 79 often pecked at the intelligence panel, the walls, and the chamber floors. The occasional within-trial keypecks that were made by these three crows appeared to be part of the generalized pecking behavior which occurred after eating, as these subjects never directed any specific body or head movements toward the key at trial onset. Crow 85 generally crouched in front of the hopper opening. During the early parts of three sessions, this crow moved directly in front of the key at trial onset. After a few trials, however, this bird resumed its former position in front of the hopper opening and no further key orientations were observed.

\section{DISCUSSION}

The present results show a clear difference in the behavior of crows and pigeons under a conventional autoshaping procedure. While the amount of keypecking was somewhat greater for the pigeons than for the crows, only one pigeon developed consistent responding of this type. However, all of the pigeons oriented toward the response key when it was illuminated, and all made pecking motions on or near the illuminated key but usually with insufficient force to activate the microswitch ("airpecking"'). The crows rarely oriented toward the response key when it was illuminated, but instead tended to orient their bodies toward the food hopper throughout each session. Several of them simply crouched in front of it until the food was presented.

While the categorization of behavior into either involuntary or voluntary components becomes increasingly problematic, such distinctions continue to be made. Schwartz (1984), for example, presents autoshaping of keypecking in pigeons as a demonstration of the control of voluntary behavior by Pavlovian contingencies. Given the ubiquitousness of pecking behavior exhibited by pigeons in the presence of food (Staddon \& Simmelhag, 1971), such behavior seems to be clearly reflexive in nature, and therefore involuntary.

As we noted in an earlier report (Powell \& Palm, 1981), the selection by Skinner of keypecking in pigeons as an arbitrary operant was a mistake. Similarly, the extensive use of this behavior in the analysis of effects produced by response-reinforcer contingencies is not advised, because of the concurrent influence of response elicitation mechanisms.

The differences between crows and pigeons in orienting behavior and subsequent pecking seem to be directly related to the stereotypical feeding behavior of the grainivorous pigeon in contrast to the varied foraging strategies of the opportunistic and omnivorous crow.

\section{REFERENCES}

Brown, P. L., \& JENKINs, H. M. (1968). Autoshaping of the pigeon's keypeck. Journal of the Experimental Analysis of Behavior, 11, 1-8.

LOWE, C. F., \& HARZEM, P. (1977). Species differences in temporal control of behavior. Journal of Experimental Analysis of Behavior, 28, 189-201.

Powell, R. W. (1972). Responding under basic schedules of reinforcement in the crow. Journal of Comparative and Physiological Psychology, 79, 156-164.

Powell, R. W. (1974). Comparison of DRL responding in pigeons and crows. Journal of Comparative and Physiological Psychology, 86, 736-746.

PoWell, R. W., \& Kelly, W. (1979). Crows learn not to respond under response-independent reinforcement. Bulletin of the Psychonomic Society, 13, 397-400.

Powell, R. W., Kelly, W., \& Santisteban, D. (1975). Responseindependent reinforcement in the crow: Failure to obtain autoshaping or positive automaintenance. Bulletin of the Psychonomic Society, 6, 513-516.

Powell, R. W., \& Palm, L. J. (1981). Responding under variableinterval, variable-time, and extinction schedules in pigeons and crows. Bulletin of the Psychonomic Society, 19, 55-58.

Schwartz, B. (1984). Psychology of Learning and Behavior. New York: Norton.

Staddon, J. E. R., \& Simmelhag, V. L. (1971). The "superstition" experiment: A reexamination of its implications for the principles of adaptive behavior. Psychological Review, 78, 3-43.

Terrace, H. S., Gibbon, J., Farrell, L., \& Baldock, M. D. (1975). Temporal factors influencing the acquisition and maintenance of the autoshaped keypeck. Animal Learning \& Behavior, 3, 53-62. 